\title{
QUASI-DETERMINED ALGORITHM FOR RESOLUTION OF RANDOMLY FLUCTUATING SIGNALS AND CHAOTIC PULSE INTERFERENCE
}

DOI: | 0.36724/2072-8735-2020-|4-2-39-44

\section{Sergey T. Yaushev,}

Kazan National Research Technical University named

after A.N. Tupolev-KAl, Kazan, Russia, yaushev.st@mail.ru

Rashid R. Faizullin,

Kazan National Research Technical University named

after A.N.Tupolev-KAl, Kazan, Russia, rrfayzullin@kai.ru

Ilya M. Lerner,

Kazan National Research Technical University named after A.N. Tupolev-KAl, Kazan, Russia, aviap@mail.ru

Keywords: quasi-determined algorithm for resolution, non-Gaussian signals, chaotic pulse interference.

\begin{abstract}
The most complete consideration of the characteristics of the signal-noise situation in the communication channel, which are determined by the probabilistic characteristics of the interference complex consisting of chaotic pulse interference, nonGaussian and noise interference with arbitrary fluctuations in the signal amplitudes and interference, is extremely important for most communication systems with moving objects. The developed method in this paper allows us to synthesize structural schemes of optimal and quasi-optimal devices for processing random groups of signals with arbitrarily defined distributions. At the same time resulting quasicanonical (unified) structures of algorithms and devices are convenient for both practical implementation and transition to adaptive procedures, when the number, vector of average values, covariance matrices and probabilities of the components of the distribution of useful and interfering pulses are estimated during signal processing and used to adapt the configuration of decision device during its work.
\end{abstract}

Information about authors:

Sergey T. Yaushev, post-graduate student, Kazan National Research Technical University named after A.N. Tupolev-KAl, Department of Nanotechnology in Electronics, Kazan, Russia

Rashid R. Faizullin, professor, doctor of Technical Sciences, Kazan National Research Technical University named after A.N. Tupolev-KAl, Department of Nanotechnology in Electronics, Kazan, Russia

Ilya M. Lerner, associated professor. candidate of physico-mathematical sciences, Kazan National Research Technical University named after A.N. Tupolev-KAl, Department of Nanotechnology in Electronics, Kazan, Russia

\section{Для цитирования:}

Яушев С.Т., Файзуллин Р.Р., Лернер И.М. Квазидетерминированный алгоритм разрешения произвольно флуктуирующих сигналов и хаотических импульсных помех // Т-Сотm: Телекоммуникации и транспорт. 2020. Том 14. №2. С. 39-44.

For citation:

Yaushev S.T., Faizullin R.R., Lerner I.M. (2020) Quasi-determined algorithm for resolution of randomly fluctuating signals and chaotic pulse interference. T-Comm, vol. 14, no.2, Pp. 39-44. (in Russian) 


\section{Introduction}

The most complete consideration of the characteristics of the signal-noise situation in the communication channel, which are determined by the probabilistic characteristics of the interference complex consisting of chaotic pulse interference, non-Gaussian and noise interference with arbitrary fluctuations in the signal amplitudes and interference, is extremely important for most communication systems with moving objects [1-6]. Therefore, when assessing the reliability of information exchange and the optimality of radio links, a necessary condition is a complete probabilistic description of the useful and interfering oscillations at the receiver input. At the same time, specific models of signals and interference should, on the one hand, correctly reflect the radio-pulse nature and type of modulation of useful signals, the shape of interference pulses, and, on the other hand, take into account their real fluctuations. For this, it is necessary to use quasi-deterministic models of signals and interference [1-3] in which elementary signals and interference pulses are described in the form of known harmonic functions of time with random parameters (amplitudes, phases, etc.).

\section{Problem Statement}

In this statement, each $j$-th multi-element signal from the ensemble $j=\overline{1, J}$ for $i=\overline{1, I}$-th type of high-frequency narrowband elementary radio signal is a sequence of high-frequency narrow-band elementary radio signals which can be represented as follows

$$
\begin{gathered}
S_{i_{j}}\left(t, \bar{\alpha}_{\mathrm{j}}\right)=\sum_{k=1}^{K} S_{i_{j k}}\left(t-t_{k}, \bar{\alpha}_{j k}\right)=\sum_{k=1}^{K} a_{i_{j k}} \operatorname{Re}\left[U_{i_{j k}}\left(t-t_{k}\right) \exp \left(j\left(2 \pi f_{0} t+\varphi_{i_{j k}}\right)\right)\right]= \\
=\sum_{k=1}^{K} a_{i_{k k}}\left(u_{i_{j k}}\left(t-t_{k}\right) \cos \left(2 \pi f_{0} t+\varphi_{i_{j k}}\right)+u_{i_{j k} \perp}\left(t-t_{k}\right) \sin \left(2 \pi f_{0} t+\varphi_{j_{j k}}\right)\right)
\end{gathered}
$$

where $I$ is the number of types of elementary high-frequency narrow-band radio signals, $J$ is the number of signal types in the ensemble, $U_{i,{ }}(\cdot)$ is complex amplitude of the narrowband modulating oscillation; $u_{i_{i k}}(t), u_{i_{i k} \perp}(t)$ are the in-phase and quadrature components of a radio signal, respectively; $\bar{\alpha}_{\mathrm{i}_{\mathrm{jk}}}=\left(a_{i_{j k}}, \varphi_{i_{j k}}\right) \in A_{\mathrm{i}}-$ random finite-dimensional parameter vectors with arbitrary probability distribution densities $w_{\mathrm{i}_{\mathrm{k}}}\left(\bar{\alpha}_{\mathrm{i}_{\mathrm{jk}}}\right)$; $t_{k}$ is a time at the $k$-th position of the signal from the start of transmission; $K$ is number of timeslot positions; $f_{0}$ is a signal carrier frequency.

In fact, in the presented model (1), the random parameters are the amplitude factors $a_{i_{j k}}$ and the initial phases $\varphi_{i_{j k}}$ of elementary signal of the $i$-th type $(i=\overline{1, I})$, corresponding to the $k$-th position of the $j$-th multi-element signal.

The distribution of the quadrature components of the signal describes the result of some random conversion by the radio channel of the parameters of this signal from the output of the transmitter, the randomness of which is caused by a variety of types and operating conditions of subscriber terminals. Signals $S_{i_{j}}\left(t, \bar{\alpha}_{\mathrm{j}}\right)$ can appear on the observation interval $T$ in random various combinations with a priori probabilities $p_{j}$. The simultaneous arrival $r=\overline{1, R}$ of signals of different types from the original ensemble is allowed.

It is assumed that in the communication channel the signal (1) is distorted by noise and chaotic impulse noise. Noise interference consists of internal and external noise, which, by virtue of generally accepted assumptions, will be considered Gaussian, having a power spectral density constant in a given band $N_{0}$. In this case, the structure of the synthesized algorithms is supplemented by a unit for estimating the noise power. Chaotic impulse noise (CIN) is formed by a finite number of $M$ independent flows of radio pulses of a known shape:

$$
\begin{gathered}
U_{C N}\left(t, \bar{t}_{m}, \bar{\beta}_{\Pi}\right)=\operatorname{Re} \sum_{m=1}^{M} b_{m}\left[U_{m}\left(t-t_{m}\right) \exp \left(j\left(2 \pi f_{0} t+\varphi_{m}\right)\right)\right]= \\
\sum_{m=1}^{M} b_{m}\left[u_{m}\left(t-t_{m}\right) \cos \left(2 \pi f_{0} t+\varphi_{m}\right)+u_{m \perp}\left(t-t_{m}\right) \sin \left(2 \pi f_{0} t+\varphi_{m}\right)\right], m=\overline{1, M} ;
\end{gathered}
$$

durations $T_{m}$ with probability densities $w_{m}\left(t_{m}, \bar{\beta}_{m}\right)$ of random parameters $\bar{\beta}_{m} \in B_{m}$ and moments of occurrence $t_{m}$. The probability of impulse interference at the $k$-th position of a multielement radio signal is denoted $p_{m}$. Here and after $b_{m}$ and $\varphi_{m}-$ a amplitude factors and initial phases for $m$-th stream of radio pulses, respectively; $u_{m}(t)$ и $u_{m \perp}$ are in-phase and quadrative components of $\mathrm{m}$-th stream of radio pulses.

All functions $S_{i_{j}}\left(t, \bar{\alpha}_{\mathrm{j}}\right)$ and $U_{C I N}\left(t, \bar{t}_{m}, \bar{\beta}_{\Pi}\right)$, by definition, have limited energy for all parameter values. Given the narrowband nature of the signals and interference, neglecting the spread of their carrier frequencies - signals, interference and the results of their interference interaction can be unambiguously described in terms of complex envelopes and their projections - quadrature components.

Accordingly, the vector of samples of the $j$-th signal during the transmission of the $k$-th code symbol (for the same elementary signals) can be written as

$$
\overline{\mathbf{u}}_{j}^{(k)}=U_{j}^{(k)} \mathbf{r}_{j}^{(k)}+U_{j \perp}^{(k)} \mathbf{r}_{j \perp}^{(k)},
$$

where $\mathbf{r}_{j}^{(k)}$ - basic nonrandom decisive functions of the reference signal obtained by multiplying the portion of the transmitted code and signature within the formation of the $k$-th bit, and $U_{j}^{(k)}$ are the random amplitudes of the quadrature components of the modulated signal.

We consider separately the situation in the absence of signals, in which an arbitrary number of $n \mathrm{CIN}$ pulses from $m$ different flows in various combinations can overlap the observation interval $T$, forming the resulting interference oscillation.

Therefore, the conditional probability density of the CIN parameter vector when applying one HIP pulse from the $m$-th stream is formed by averaging the joint probability density of the $w_{m_{1}}\left(t_{m_{1}}, \overline{\beta_{m_{1}}}\right)$ parameters of the fixed CIN pulse over all $M$-flows of HIP with the corresponding conditional probabilities $p_{m}$ :

$$
w_{1}\left(\bar{t}_{n}, \bar{\beta}^{(1)}\right)=\sum_{m_{1}=0}^{M} p_{m_{1}} w_{m_{1}}\left(t_{m_{1}}, \overline{\beta_{m_{1}}}\right), \bar{\beta}^{(1)} \in \prod_{m=0}^{M} B_{m},
$$

where $t_{m_{1}}$ - moment of occurrence of the CIN impulse, $p_{m_{1}}-$ conditional probability of overlapping on the interval of one impulse from the $m$-th CIN stream. 
Accordingly, the conditional probability density of the pulse parameters of the resulting interfering vibration $\bar{U}_{n}\left(\bar{t}_{n}, \bar{\beta}^{(n)}\right)$ is defined as:

$$
\begin{gathered}
w_{n}\left(\bar{t}_{n}, \bar{\beta}^{(n)}\right)=\sum_{m_{1}=0}^{M} \ldots \sum_{m_{n}=0}^{M} p_{m_{1}, \ldots, m_{n}} w_{m_{1}, \ldots, m_{n}}\left(t_{m_{1}}, \overline{\beta_{m_{1}}}, \ldots, t_{m_{n}}, \overline{\beta_{m_{n}}}\right), \\
\bar{\beta}^{(n)} \in \prod_{m=0}^{M}\left(B_{m}\right)^{n}, \overline{t_{n}}=\left\{t_{m_{1}}, t_{m_{2}}, \ldots, t_{m_{n}}\right\},
\end{gathered}
$$

where $p_{m_{1}, \ldots, m_{n}}=\prod_{k=1}^{n} p_{m k}-$ conditional overlap probability of $n$ CIN pulses from $m$-streams with numbers $m_{1} \ldots m_{n} ; w_{m_{1} \ldots m_{n}}(\bullet)$ is joint probability density of superimposed CIN pulse parameters.

In accordance with the formula for total probability, the unconditional probability density of the parameters of the resulting interference oscillation describes the result of interference of a fixed number of CIN pulses and has the following form:

$$
\begin{aligned}
& w\left(\overline{t_{n}}, \bar{B}\right)=\sum_{n=0}^{N} p_{n} \sum_{m_{1}=0}^{M} \ldots \sum_{m_{n}=0}^{M} p_{m_{1}, \ldots, m_{n}} w_{m_{1}, \ldots, m_{n}}\left(t_{m_{1}}, \overline{\beta_{m_{1}}}, \ldots, t_{m_{n}}, \overline{\beta_{m_{n}}}\right) \\
& \bar{B} \in \sum_{n=0}^{N} \beta^{(n)}, \overline{t_{n}} \in T=\prod_{n=0}^{N}\left(\prod_{m=0}^{M}\left(T_{n}+T_{m}\right)\right)^{n}, \sum_{n=0}^{N} p_{n}=1 .
\end{aligned}
$$

Let us consider interference situations, assuming the twocomponent composition of the $\bar{\beta}_{m}=\left(b_{m}, \varphi_{m}\right)$ parameter vector with a random amplitude factor $b_{m}$ and an initial phase $\varphi_{m}$, the joint density of which is $w\left(b_{m}, \varphi_{m}\right)$, and the arrival times $\left\{t_{m}\right\}$ are fixed during the implementation of the resulting CIN pulse.

We introduce a Gaussian density corresponding to centered noise with a constant power density within the signal spectrum $N_{0}$ and CIN and write the unconditional density of the input process as a weighted sum of conditional distributions averaged over random parameters of the corresponding CIN pulses:

$$
w_{n}(\bar{u})=\sum_{n=0}^{N} p_{n} \iint_{\bar{T}} w_{\bar{B}}\left(\bar{t}_{n}, \bar{\beta}^{(n)}\right) N\left(\bar{U}, \bar{U}_{n}\left(\bar{t}_{n}, \bar{\beta}^{(n)}\right), N_{0}\right) d \overline{t_{n}} d \bar{\beta} .
$$

Due to the fact that the instantaneous values of a narrow-band random signal are described by a poly-Gaussian model, as shown in [10], the envelope value of this signal is distributed according to the poly-Rice law. Then, for signals and interference of the form (1) and (2) with arbitrary given probability densities $w_{i}\left(a_{i}\right)$ and $w_{m}\left(b_{m}\right)$ of random multipliers $a_{i}$ and $b_{m}$ of complex envelopes of amplitudes of useful signals and CIN and with an initial phases $\varphi_{i}$ and $\varphi_{m}$, respectively, distributed uniformly in the interval $(0, \pi)$, against the background of noise with a uniform spectral power density, the amplitude fluctuations of the pulses of the signals and HIP, at the output of the linear detector are represented by the poly-Rice densities of dimensionless coefficients $a_{i}$ and $b_{m}$ :

$$
\begin{aligned}
& w_{i}\left(a_{i}\right)=\sum_{n_{i}=1}^{N_{i}} q_{n_{i}} \frac{a_{i}}{\sigma_{i}^{2}} \exp \left\{-\frac{a_{i}^{2}+m_{n_{i}}^{2}}{2 \sigma_{i}^{2}}\right\} I_{0}\left\{\frac{m_{n i} a_{i}}{\sigma_{i}^{2}}\right\} ; \quad i=\overline{1, J} \\
& w_{m}\left(b_{m}\right)=\sum_{n_{m}=1}^{N_{m}} q_{n_{m}} \frac{b_{m}}{\sigma_{m}^{2}} \exp \left\{-\frac{b_{m}^{2}+m_{m}^{2}}{2 \sigma_{m}^{2}}\right\} I_{0}\left\{\frac{m_{n_{m}} b_{m}}{\sigma_{m}^{2}}\right\}, \quad \mathrm{m}=\overline{1, M},
\end{aligned}
$$

where $\sigma_{i}^{2}$ and $\sigma_{m}^{2}$-dispersion of signal amplitudes and interference; $N_{i}, q_{n_{m}}$ and $N_{m}, q_{n_{m}}$ are the number and probabilities of the Rice components of the $i$-th signal and interference from the $m$-th CIN stream; $m_{n_{i}}$ and $m_{n_{m}}$ are the parameters of the Rice probability densities of the $i$-th signal and interference from the $m$-th CIN stream; $I_{0}\{\}$ - a modified Bessel function of the first kind of zero order of an imaginary argument.

To calculate probability densities of the form (5), we use the technique developed by Profess or Ya. D. Shirman [8] and developed for signal processing algorithms based on the use of polyGaussian models in [9]. This technique is based on a composition of the distribution laws and is associated with a recursive calculation of the probability densities of noise and $m$ - $t h$ interfering pulses:

$$
\begin{aligned}
& w^{n u}(\bar{U})=w^{m}(\bar{U})=\int_{0}^{2 \pi} w\left(\varphi_{m}\right) d \varphi_{m} \int_{0}^{\infty} w\left(b_{m}\right) w^{m-1} \times . \\
& \left.\times\left[\bar{U}_{m} \cos \varphi_{m}+\bar{U}_{m \perp} \sin \varphi_{m}\right)\right] d b_{m} .
\end{aligned}
$$

Taking into account the Poly-Rayleigh distribution of the $b_{m}$ random amplitude factor of the equiprobable distribution of the initial phases, expression (8) is transformed to:

$$
\begin{aligned}
& w^{m}(\bar{U})=\frac{1}{2 \pi} \sum_{n_{n_{m}}}^{N_{m m}} q_{n_{n n}} \int_{0}^{2 \pi} \int_{0}^{\infty} \frac{b_{m}}{\sigma_{n_{m m}}^{2}} \times \\
& \times \exp \left(-\frac{b_{m}^{2}}{2 \sigma_{n_{m m}}^{2}}\right) w^{m-1}\left[\bar{U}-b_{m}\left(\bar{U}_{m} \cos \varphi_{m}+\bar{U}_{m \perp} \sin \varphi_{m}\right)\right] d \phi_{m} d b_{m}
\end{aligned}
$$

Thus, a recurrence calculation of densities of the form (11) of the input implementation vector is carried out, provided that the observed oscillation contains one CIN pulse, two CIN pulses, .... $m$ pulses. The structure of the final expressions for the probability densities of the input voltage vector $w^{m}(\bar{U})$ of the receiver remains unchanged and each time (at each recursion) depends on the value of the probability density calculated in the previous step.

In accordance with the methodology for the synthesis of decisive statistics, having performed the transformations associated with the replacement of variables by moving to Cartesian coordinates, we write the recurrence expression for the density (11):

$$
\begin{aligned}
& w^{m}(\bar{U})=\sum_{n_{n_{m}}}^{N_{n_{m}}} q_{n_{n_{m}}} w^{m-1}(\bar{U}) \frac{N_{0}}{2 \bar{U}_{n_{m}} \bar{r}_{n_{n_{m}}^{m}}^{m} \sigma_{n_{n_{m}}}^{2}+N_{0}} \times, \\
& \times \exp \left[\frac{2 \sigma_{n_{n_{m}}}^{2}}{N_{0}} \frac{\left(\bar{U} \bar{r}_{n_{n_{m}}}^{m}\right)^{2}+\left(\bar{U} \bar{r}_{n_{n_{\perp}}}^{m}\right)^{2}}{2 \bar{U}_{n_{m}} \bar{r}_{n_{m_{\perp}}^{m}}^{m} \sigma_{n_{n_{m}}}^{2}}\right]
\end{aligned}
$$

where $\bar{r}_{n_{n_{m}}^{m}}^{m}$ and $\bar{r}_{n_{n_{m_{\perp}}}^{m}}^{m}$ - basic decision functions containing decision functions; $\bar{r}_{n_{n_{k}}}^{k}$ - obtained by recursive calculations at the previous stages and corresponding to interference-superposition combinations that are calculated for each $n$ component of the initial distribution (8) are nonrandom reference voltage functions and determine the decisive correlation processing function $\bar{R}_{n}^{m}=\bar{r}_{n}^{m}+j \bar{r}_{n_{\perp}}^{m}:$

$$
\begin{aligned}
& \bar{r}_{n_{n_{m}}}^{m}=\bar{U}_{n_{m}}-2 \sigma_{n_{n_{k}}}^{2} \sum_{k=1}^{m-1} \frac{\bar{r}_{m_{k k}}^{k}\left(\bar{U}_{n_{m}} \bar{r}_{n_{k k}}^{k}\right)+\bar{r}_{n_{n} k_{1}}^{k}\left(\bar{U}_{n_{m} \perp} \bar{r}_{n_{n} k \perp}^{k}\right)}{2 \bar{U}_{n_{k}} \bar{r}_{n_{n k}}^{k} \sigma_{n_{n k}}^{2}+N_{0}} ; \\
& \bar{r}_{n_{m \perp \perp}}^{m}=\bar{U}_{n_{m \perp}}-2 \sigma_{n_{n k}}^{2} \sum_{k=1}^{m-1} \frac{\bar{r}_{n_{n k}}^{k}\left(\bar{u}_{n_{m \perp}} \bar{r}_{n_{n k}}^{k}\right)+\bar{r}_{n_{n k \perp}}^{k}\left(\bar{U}_{n_{m \perp}} \bar{r}_{n_{n} k_{1}}^{k}\right)}{2 \bar{U}_{n_{k}} \bar{r}_{n_{n k}}^{k} \sigma_{n_{n k}}^{2}+N_{0}}
\end{aligned}
$$


Just as the equiprobability of the initial phase of the carrier oscillation of the initial radio pulse is characteristic of its Rayleigh components, randomness and probability density of the moment of arrival of the radio signals are transferred to them from the original signal. Therefore, an arbitrarily fluctuating radio pulse with a random arrival time is represented as a mixture of Rice-Rayleigh radio pulses with equally probable initial phases and with the same distribution of arrival times.

Considering the realization of CIN pulses to be the average values of the corresponding Gaussian processes, taking into account (6) and (7), we write down the density corresponding to the superposition of $n$-pulses from $m$-HIP flows:

$$
\begin{aligned}
& w_{n_{u}}^{n}(\bar{U})=\sum_{n=0}^{N} p_{n} \sum_{m_{1}=0}^{M} \ldots \sum_{m_{n}=0}^{M} p_{m_{1} \ldots m_{n}} \sum_{n_{n_{n}}=1}^{N_{n_{n}}} q_{n_{n_{n}}} \int_{-T_{m_{1}}}^{T_{n}} \ldots \int_{-T_{m_{n}}}^{T_{n}} w^{n-1}(\bar{U}) \times \\
& \times \exp \left[\frac{2 \sigma_{n_{n_{n}}}^{2}}{N_{0}} \frac{\left[\bar{U}\left(t_{m_{n}}\right)_{n_{n_{n}}}^{2}\right]^{2}+\left[\bar{U}\left(t_{m_{n^{\prime}}}\right) \bar{r}_{n_{n_{n}}}^{2}\right]^{2}}{2\left(\bar{U}_{n_{n}} \bar{r}_{n_{n}}^{2}\right) \sigma_{n_{n_{n}}}^{2}} w_{m_{1} . . n_{n}}\left(t_{m_{m}}, \ldots, t_{m_{n}}\right) d t_{m_{1}} \ldots d t_{m_{n}}\right.
\end{aligned}
$$

Similar reasoning is valid for the case of superposition $\gamma_{i}$ of signals $\bar{S}_{i}(\vec{\alpha}), i=\overline{1, J}$ in the considered interference complex and leads to the expression for the density corresponding to the complex of signals, CIN and noise to the following form:

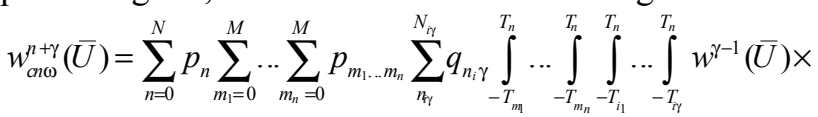

$$
\begin{aligned}
& \times \frac{N_{0}}{2\left(\bar{S}_{\dot{\gamma}_{\gamma}} \bar{r}_{n_{\gamma \gamma}}^{n+\gamma}\right) \sigma_{n_{i_{\gamma}}}^{2}+N_{0}} \exp \left[\frac{2 \sigma_{n_{\gamma \gamma}}^{2}\left[\bar{U}\left(t_{i}, \ldots, t_{i \gamma}\right) \bar{r}_{n_{i \gamma}}^{n+\gamma}\right]^{2}}{2\left(\bar{S}_{\hat{\lambda}} \bar{r}_{n \bar{\gamma}}^{n+\gamma}\right) \sigma_{n_{\gamma \gamma}}^{2}}\right] \times \\
& \times w_{m_{1} \ldots m_{n}}\left(t_{m_{1}, \ldots, m_{n}} t_{m_{n}}\right) w_{i_{, ., i_{\gamma}}}\left(t_{i_{1}, \ldots, \ldots} t_{i \gamma}\right) d t_{m_{1} \ldots} \ldots d t_{m_{n}} d t_{i_{1}} \ldots d t_{i_{\gamma}}
\end{aligned}
$$

\section{Synthesis of a poly-Gaussian algorithm for resolving quasi-deterministic signals against the background of HIP and noise}

Based on the method of poly-Gaussian synthesis of reception algorithms [10,11] and passing to the expressions of polyGaussian likelihood ratios, we obtain that in the case of applying one useful signal in the HIP complex, we have the following expression structure:

$$
\begin{aligned}
& \ell^{n+1}(\bar{U})=\sum_{n_{1}=1}^{N_{i_{1}}} q_{n_{i_{1}}} \int_{-T_{i_{1}}}^{T_{n}} \frac{N_{0}}{2\left(\overline{S_{i_{1}}} \bar{r}_{n_{i_{1}}}^{n+1}\right) \sigma_{i_{i_{1}}}^{2}+N_{0}} \exp \times \\
& \times\left[\frac{\left.\left.2 \sigma_{n_{n_{1}}}^{2}\left(\bar{U}\left(t_{i_{1}}\right) \bar{r}_{n_{i_{1}}}^{n+1}\right)\right)^{2}+\left(\bar{U}\left(t_{i_{1}}\right) \bar{n}_{n_{i \perp \perp}}^{n+1}\right)\right)^{2}}{N_{0}\left(\bar{S}_{i_{1}} \bar{r}_{n_{i_{1}}}^{n+1}\right) \sigma_{n_{i_{1}}}^{2}}\right] \times w_{i_{i_{1}}}\left(t_{i_{1}}\right) d t_{i_{1}} .
\end{aligned}
$$

Provided that two useful signals with random moments of arrival overlap the observation interval, the likelihood ratio expression initially takes the form:

$$
\begin{aligned}
& \ell^{n+2}(\bar{U})=\sum_{n_{i 2}=1}^{N_{i_{2}}} q_{n_{i_{2}}} \int_{-T_{i_{2}}}^{T_{n}} \int_{-T_{i}}^{T_{n}} \int_{\varphi_{i_{2}}} \int_{i_{i 2}} w\left(t_{i_{2}}, \varphi_{i_{2}}, a_{i_{2}}\right) \times \\
& \times \frac{w^{n+2}\left[\bar{U}-a_{i_{2}}\left(\bar{S}_{i_{2}} \cos \varphi_{i_{12}}+\bar{S}_{i_{1} \perp} \sin \varphi_{i_{2}}\right)\right]}{w^{n}(\bar{U})} d t_{i_{2}} d t_{i_{1}} d \varphi_{i_{2}} d a_{i_{2}} .
\end{aligned}
$$

where $w^{n+2}(\bullet)$ decomposes recursively into expressions, one of which will be $w^{n+1}(\bar{U})$, the structure of which is obvious from expression (16) and from which, in its turn, a member $w^{n}(\bar{U})$ is distinguished.

Therefore, the expression for the following hypothesis takes the form:

$$
\begin{aligned}
& l^{n+2}(\bar{U})=\sum_{n_{1}=1}^{N_{i_{1}}} \sum_{n_{12}=1}^{N_{i_{2}}} q_{n_{1}} q_{n_{i_{2}}} \int_{-T_{i_{1}}-T_{i_{2}}}^{T_{n_{1}}} \int_{T_{n j}}^{T_{n}} \frac{N_{0}}{2\left(\bar{S}_{i_{1}} \bar{r}_{n_{1}}^{n+1}\right) \sigma_{n_{1}}^{2}+N_{0}} \exp \left[\frac{2 \sigma_{n_{1}}^{2}}{N_{0}}\right] \times \\
& \times \frac{\left[\bar{u}\left(t_{i_{1}}\right) r_{n_{i}}^{-n+1}\right]^{2}+\left[\bar{u}\left(t_{i_{2}}\right) r_{n_{2 \perp}}^{-n+2}\right]^{2}}{2\left(\bar{S}_{i_{1}} \bar{r}_{n_{1}}^{n+2}\right) \sigma_{n_{i_{1}}}^{2}} \cdot \frac{N_{0}}{2\left(\bar{S}_{i_{2}} \bar{r}_{n_{2}}^{n+2}\right) \sigma_{n_{i 2}}^{2}+N_{0}} \exp \left[\frac{2 \sigma_{n_{i_{2}}}^{2}}{N_{0}}\right] \times \\
& \times \frac{\left[\bar{u}\left(t_{i_{2}}\right) r_{n_{i_{2}}}^{-n+2}\right]^{2}+\left[\bar{u}\left(t_{i_{i}}\right) r_{n_{i_{1}}}^{-n+2}\right]^{2}}{2\left(\bar{S}_{i_{2}} \bar{r}_{i_{21}}^{n+2}\right) \sigma_{n_{i_{2}}}^{2}} w_{i_{1}} w_{i_{2}}\left(t_{i_{1}}, t_{i_{12}}\right) d t_{i_{1}} d t_{i_{2}} .
\end{aligned}
$$

Thus, taking into account the "nesting" of densities of the form (12), the likelihood ratio for an arbitrary case of overlapping a random number $\gamma_{i}$ of useful signals $\bar{S}_{i} ; i=\overline{1, J}$ with a complex of CIN and noise can be written in the following constructive form:

$$
\begin{aligned}
& l^{n+\gamma}(\bar{u})=\sum_{n_{1}=1}^{N_{i_{1}}} \ldots \sum_{n_{i_{i}}=1}^{N_{i_{\gamma}}} q_{n i_{1}} \ldots q_{n i_{\gamma}} \int_{-T_{n_{1}}}^{T_{H}} \ldots \int_{-T_{n i}}^{T_{H}} \prod_{k=1}^{\gamma} \frac{N_{0}}{2\left(\bar{S}_{i_{k}} \bar{r}_{n_{i_{k}}}^{n+k}\right) \sigma_{n_{i_{k}}}^{2}+N_{0}} \times \\
& \times \exp \left[\frac{2 \sigma_{n_{i_{k}}}^{2}}{N_{0}} \frac{\left[\bar{u}\left(t_{i_{1}}, \ldots, t_{i_{r}}\right) r_{n_{i_{k}}}^{-n+k}\right]^{2}+\left[\bar{u}\left(t_{i_{1}}, \ldots, t_{i_{\gamma}}\right) r_{n_{i_{1}}}^{-n+k}\right]^{2}}{2\left(\bar{S}_{i_{k}} \bar{r}_{n_{i_{k}}}^{n+k}\right) \sigma_{n_{i_{k}}}^{2}+N_{0}}\right] \times \\
& \times w_{i_{1}}, \ldots, i_{k}\left(t_{i}, \ldots, t_{i k}\right) \times d t_{i} \ldots d t_{i k},
\end{aligned}
$$

where under the sign $\prod_{k=1}^{\gamma}$ of the product are the Rayleigh likelihood relationships, the indexing of the variables in which takes into account the belonging to the component number in the corresponding Rayleigh representation of the signal, to the type of signal, as well as the number of valid useful signals.

If we consider the structure of the Rayleigh likelihood ratio then it is easy to notice that $2 \bar{S}_{i_{k}} \bar{r}_{n_{i k}}^{n+k} \sigma_{n_{i k}}^{2}$ is an energy of the $n$-th component of the $i_{k}$ signal, taking into account the fact of interaction with a random number $(n+k)$ of interference and signals we denote it as $\exists_{n_{i k}}^{m+k}$, and the term

$$
\left(\left[\bar{u}\left(t_{i_{1}}, \ldots, t_{i_{k}}\right) \bar{r}_{n_{i_{k}}}^{n+k}\right]^{2}+\left[\bar{u}\left(t_{i_{1}}, \ldots, t_{i_{k}}\right) \bar{r}_{n_{i_{k}}}^{n+k}\right]^{2}\right)
$$

is the modular value of the correlation integral, which we denot $\epsilon$ as $Z_{n_{i k}}^{n+k}(\bar{U})$. Given the accepted notation, we obtain:

$$
\begin{aligned}
& l^{n+\gamma}(\bar{u})=\sum_{n_{1}=1}^{N_{i_{1}}} \ldots \sum_{n_{\gamma}=1}^{N_{i_{\gamma}}} q_{n i_{1}} \ldots q_{n i_{\gamma}} \int_{-T_{n_{1}}}^{T_{H}} \ldots \int_{-T_{n_{\gamma}}}^{T_{H}} \prod_{k=1}^{\gamma} \frac{N_{0}}{\Im_{n_{i_{k}}}^{n+k}\left(t_{i_{1}}, \ldots, t_{i_{k}}\right)+N_{0}} \times \\
& \times \exp \left[\frac{2 \sigma_{n_{i_{k}}}^{2}}{N_{0}} \frac{\mathrm{Z}\left[\bar{u}\left(t_{i_{1}}, \ldots, t_{i_{k}}\right)\right.}{\Im_{n_{i_{k}}}^{n+k}\left(t_{i_{1}}, \ldots, t_{i_{k}}\right)+N_{0}}\right] w_{i_{1}}, \ldots, i_{k_{k}}\left(t_{i}, \ldots, t_{i k}\right) d t_{i} \ldots d t_{i_{k}} .
\end{aligned}
$$

The resulting expression reflects many complex hypotheses about the interference of noise, $n$ CIN pulses and $\gamma$ signals, and averages the exponentially transformed squares of the modules of correlation integrals correspond ing to simple hypotheses over the time of arrival of the signals.

The structure of expression (20) completely determines the multi-level hierarchical structure of the poly-Gaussian algorithm for resolving quasi-determined signals against the background of pulsed interference and noise. In the structure of the algorithm. many parallel branches are formed, in each of which the partial 
functionals of the Rice-Rayleigh likelihood relations are calculated. Each branch is formed by a direct product of the corresponding Rayleigh likelihood relations, and on each tier, depending on the number of superimposed signals, their weighted summation is carried out.

Figure 1 shows the structural diagram of a device that implements the obtained algorithm for resolving multi-element signals in the HIP complex. The device contains a set of parallel channels $\left(1_{1}-1_{H}\right)$ for processing signals and interference. Each of the signal processing channels contains a polycorrelation signal processing unit 4 and summation blocks $\left(5_{0}-5_{L}\right)$, where signals are generated that are proportional to the linear combination of particular likelihood ratio functionals for all signal-noise components. The number of signal processing channels is equal to the specified number of superimposed combinations of allowed signals.

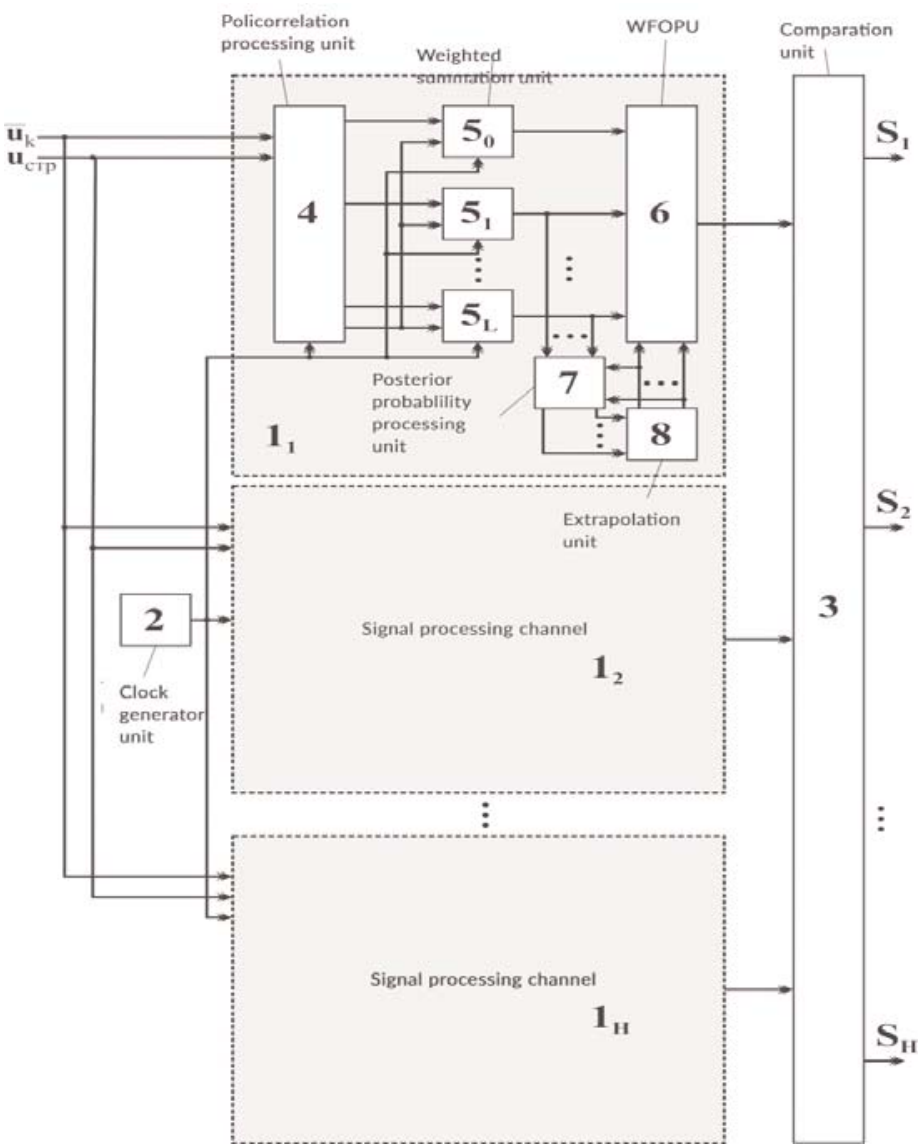

Fig. 1. Block diagram of an adaptive resolution device MS-PG multi-element signals

In each processing channel, there is a block 6 for calculating the final likelihood ratio functional of the current combination of overlapping resolved signals. The signal inputs of this block are connected to the corresponding signal outputs of the summing blocks $\left(5_{0}-5_{L}\right)$, the output signals of which are connected to the inputs of block 7 for calculating the posterior probabilities of the combinations of numbers of the Gaussian components of the allowed signals.

In the general case, the number of possible hypotheses calculated during the operation of the algorithm is determined as

$$
H=\frac{(J+R) !}{J ! R !}
$$

where $R$ - a maximum number of signals simultaneously present in the input oscillation.

\section{Conclusion}

It is known that the optimal receiver exists strictly within the framework of the problem in which it is synthesized. Since a comprehensive description of real signal-noise situations is extremely difficult, and the selected quality criterion brings errors in one way or another, the question of the synthesis of quasioptimal reception algorithms becomes relevant.

It is important that the class of poly-Gaussian algorithms allows controlling the proximity of the synthesized algorithm to the optimal solution by optimizing the number of hypotheses taken into account and, when using the poly-Gaussian representation of signals and noise, use no more than 3-4 components of the probability decomposition. Indeed, the most complex hypotheses are the least likely and reflect the unlikely fact of multiple superposition of signals and impulse noise.

Many radio links are characterized by a significant excess of the average power of the interfering pulse over the noise spectral density. Therefore, with powerful CIN pulses with arbitrary durations, the algorithm, using the replacement of complex hypotheses about applying CIN with the most plausible hypotheses, is quasioptimal. If the CIN pulses do not exceed the noise level, then it is advisable to abandon the distinction of the moment of arrival of CIN, considering only two hypotheses - the imposition and absence ofCIN.

Thus, the arbitrary probability distributions of the parameters of radio pulses that actually exist in the radio links of mobile communication systems allow uniform representations (in the sense of mixtures of probability distributions) and require the fulfillment of two conditions: physical realizability and statistical stability.

\section{References}

1. Sosulin Y. (1978), The theory of detection and estimation of stochastic signals. Moscow. $320 \mathrm{p}$.

2. Faizullin R.R. and etc. (2018), "Performance Analysis of the EM Algorithm in Conjunction with Algorithms for Determining an Optimal Number of Clusters and Their Centroids, Which Allows Estimating Parameters of NonGaussian Interference in Mobile Communication Systems", Russ. Aeronaut., No. 3, pp. $487-494$.

3. Lemer I.M., Faizullin R.R., Yaushev S.T. (2019), About increasing the throughput of wireless communication systems with PSK-n-signals in communication channels with intersymbol distortions. Bulletin of KSTU named after A.N. Tupolev. No. 4, pp. 159-168.

4. Lerner I. M. and Il' in G. I. (2017), "Possibility of increasing the data transmission rate in the presence of destabilizing factors in communication systems using symbols with mutual interference", Physics of Wave Processes and Radio Engineering Systems, No. 4. pp. 24-34.

5. Lemer I. M., Il'in G.I., Khayrul lin M.I. (2016), "To a question of complex noises and interference generating" Physics of Wave Processes and Radio Engineering Systems. No. 2, pp. 23-26.

6. Lemer I.M. (2019). Influence of the shape of the amplitude-frequency response on the capacity of communication channel with memory using APSK-N signals, which implements the theory of resolution time. T-Comm. Vol. 13. No. 10, pp. 45-59.

7. Chabdarov Sh.M. (1974) Optimal receiving for arbitrary fluctuations of impulse noise and signals. Radiotekhnika i elektronika, No. 5, pp. 1082-1086.

8. Shirman YA.(1974) Signal Resolution and Compression. Moscow. 360 p.

9. Chabdarov Sh.M. (1979), Polygaussian receivers of arbitrarily fluctuating signals and interference, Radio Engineering and Electronic Physics. No. 9, pp. 32-38.

10. Chabdarov Sh.M., Faizullin R.R., Nadeev A.F. (2014), Post-correlation probabilistic models in the problem of signal discrimination for modern information and communication systems, Russ. Aeronaut. Vol. 52. No. 2, pp. 175-180.

11. Chabdarov Sh.M., Trofimov A.T. (1975), Polygaussian representations of arbitrary interference and reception of discrete signals. Radiotekhnika $i$ elektronika. Vol. 4. No. 20, pp. 734-735. 
ELECTRONICS. RADIO ENGINEERING

\section{КВАЗИДЕТЕРМИНИРОВАННЫЙ АЛГОРИТМ РАЗРЕШЕНИЯ ПРОИЗВОЛЬНО ФЛУКТУИРУЮЩИХ СИГНАЛОВ И ХАОТИЧЕСКИХ ИМПУЛЬСНЫХ ПОМЕХ}

Яушев Сергей Тимурович, Казанский национальный исследовательский технический университет им. А.Н. Туполева - КАИ, Казань, Россия, yaushev.st@mail.ru

Файзуллин Раиид Робертович, Казанский национальный исследовательский технический университет им. А.Н. Туполева - КАИ, Казань, Россия, rrfayzullin@kai.ru

Лернер Илья Михайлович, Казанский национальный исследовательский технический университет им. А.Н. Туполева - КАИ,

Казань, Россия, aviap@mail.ru

\section{Аннотация}

Описанная методика позволяет синтезировать структурные схемы оптимальных и квазиоптимальных устройств обработки случайных групп сигналов с произвольно задаваемыми распределениями, а получаемые квазиканонические (унифицированные) структуры алгоритмов и устройств удобны как для практической реализации, так и для перехода к адаптивным процедурам, когда количество, вектора средних значений, ковариационные матрицы и вероятности компонент распределения полезных и мешающих импульсов оцениваются в процессе работы и используются для перестройки решающей схемы приемника обработки сигналов в сложных помеховых комплексах.

Ключевые слова: квазидетерминированный алгорим разрешения, негауссовские сигналы, хаотические импульсные помехи.

\section{Литература}

І. Сосулин Ю. Теория обнаружения и оценивания стохастических сигналов, 1978, Вып. М.: Сов. радио. 320 с.

2. Faizullin R.R. и дp. Performance Analysis of the EM Algorithm in Conjunction with Algorithms for Determining an Optimal Number of Clusters and Their Centroids, Which Allows Estimating Parameters of Non-Gaussian Interference in Mobile Communication Systems // Russ. Aeronaut. 2018. T. 6I. № 3, pp. 487-494.

3. Лернер И.М., Файзуллин Р.Р., Яушев С.Т. О повышении пропускной способности беспроводных систем связи с ФМн-n- сигналами в каналах связи с межсимвольными искажениями // Вестник КГТУ. 2019, № 3. С. 159-168.

4. Лернер И.М., Ильин Г.И. Об одной возможности увеличения скорости передачи при наличии дестабилизирующих факторов в системах связи, использующих взаимную интерференцию символов // Физика волновых процессов и радиотехнические системы, 20І7. №4. С. 24-34.

5. Лернер И.М., Ильин Г.И., Хайруллин М.И. К вопросу формирования шумов и помех в комплексном виде // Физика волновых процессов и радиотехнические системы, 2016. №2. С. 23-26.

6. Лернер И.М. К вопросу оптимизации амплитудно-частотных характеристик каналов связи с ФМн-n-сигналами, построенных на основе теории разрешающего времени // Т-Сотm: Телекоммуникации и транспорт. 2019. Том I3. №9. С. 36-49.

7. Чабдаров Ш.М. Оптимальный прием при произвольных флуктуациях импульсных помех и сигналов // Радиотехника и электроника. 1979. Т.24. №5. C. $1082-1086$.

8. Ширман Я. Разрешение и сжатие сигналов. 1974. М.: Сов. радио. 360 с.

9. Чабдаров Ш.М. Полигауссовы приемники произвольно флуктуирующих сигналов и помех // Радиоэлектроника. Т.20. №9. С. 32-38.

10. Chabdarov S.M., Faizullin R.R., Nadeev A.F. Post-correlation probabilistic models in the problem of signal discrimination for modern information and communication systems // Russ. Aeronaut. 2014. T. 52. № 2. C. 175-180.

II. Чабдаров Ш.М., Трофимов А.Т. Полигауссовы представления произвольных помех и прием дискретных сигналов // Радиотехника и электроника, 1975. T. 4. № 20. C. $734-735$.

Информация об авторах:

Яушев Сергей Тимурович, аспирант кафедры НТвЭ, Казанский национальный исследовательский технический университет им. А.Н. Туполева КАИ, Казань, Россия

Файзуллин Рашид Робертович, д.т.н., зав. кафедрой НТвЭ, Казанский национальный исследовательский технический университет им. А.Н. Туполева - КАИ, Казань, Россия

Лернер Илья Михайлович, к.ф.-м.н., доцент кафедры НТвЭ, Казанский национальный исследовательский технический университет им. А.Н. Туполева - КАИ, Казань, Россия 